$\Delta$ Palabras clave/ Historia urbana, barrio El Aguilucho, Providencia, historia de Santiago

$\Delta$ Keywords/ Urban history, El Aguilucho quarter. Providencia, history of Santiago.

$\Delta$ Recepción/ 15 diciembre 2017

$\Delta$ Aceptación/ 24 mayo 2018

\title{
El barrio construido y habitado como valor histórico y social: El caso de El Aguilucho en Santiago de Chile $^{1}$
}

\section{The Built and Inhabited Neighborhood as} a Historic and Social Value: The Case of El Aguilucho in Santiago, Chile ${ }^{1}$

\section{Uri Colodro-Gotthelf}

Geógrafo, Pontificia Universidad Católica de Chile, Chile.

Master of Science in Governance of Risks and Resources, Ruprecht-Karls Universität Heidelberg, Alemania.

Geógrafo, Centro de Desarrollo Urbano Sustentable (CEDEUS), Santiago de Chile, Chile. jucolodr@uc.cl

RESUMEN/ El barrio El Aguilucho es un espacio de frontera al sur de la comuna de Providencia, en el sector oriente de Santiago de Chile. Este territorio tiene una singular antigüedad y origen popular que lo distingue de su entorno, generándose una vida 'de pueblo' inmersa en un espacio metropolitano, así como una tipología particular de relaciones sociales. El presente trabajo rescata sus transformaciones urbanas, origen e historia. ABSTRACT/ El Aguilucho is a boundary neighborhood that lies in the southern part of the commune of Providencia, in the eastern area of Santiago, Chile. This old quarter has a remarkable working-class origin that distinguishes it from its surrounding areas, resulting in a village-like' lifestyle immersed in a metropolitan space, as well as particular types of social relations. The following research recovers its urban transformations, as well as its origin and history.

INTRODUCCIÓN. El barrio El Aguilucho corresponde a una de las primeras urbanizaciones de la comuna de Providencia en Santiago de Chile. Tanto su antigüedad y características morfológicas, como los valores, oficios y modo de vida de sus habitantes, han configurado un territorio de especial singularidad, donde se valora la 'vida de barrio' y una forma de socialización cada vez más escasa en una metrópolis que aglomera a más de seis millones de habitantes. Se trata de un caso único en cuanto a su evolución histórica, pero que guarda relación con otros barrios del pericentro de Santiago a la hora de pensar en sus transformaciones más recientes, asociadas a un proceso de gentrificación.
El objetivo del presente artículo es reconstruir los antecedentes históricos del proceso de urbanización y transformaciones socio-territoriales del barrio El Aguilucho, como una primera caracterización para la comprensión y entendimiento de las lógicas espaciales de este territorio. Esta se inserta en el contexto de una investigación de mayor envergadura, la cual analiza la forma en que las gobernanzas de los diversos actores presentes en el barrio El Aguilucho han influido en la instalación de un proceso de gentrificación comercial y residencial en las últimas tres décadas.

La reconstrucción de este relato histórico fue resuelta metodológicamente a través de la compilación y análisis de información de carácter bibliográfico, y la realización de entrevistas semi-estructuradas a actores clave. Se llevaron a cabo visitas a las bibliotecas de Lo Contador y Nacional de Chile, obteniéndose fuentes primarias como antiguos diarios, revistas, cartografías y fotografías; asimismo, se consultaron fuentes secundarias como libros, tesis y artículos académicos. Por otro lado, se entrevistó a 13 personas de procedencias variadas y que guardan algún tipo de relación con el barrio. El muestreo fue de carácter discriminativo, escogiéndose específicamente a los actores clave de acuerdo con sus funciones, a partir de pesquisas previas. Así, surgieron recomendaciones de otros actores a entrevistar, generándose un proceso 'bola de nieve' en su selección. 


\section{UN PASADO RURAL Y UN PRESENTE DE CENTRALIDAD: Las comunas de Providencia y Ñuñoa en el contexto del Gran Santiago. Hasta la segunda} mitad del siglo XIX, la ciudad de Santiago tenía definidos sus límites hacia el oriente por el Camino de Cintura, actual avenida Vicuña Mackenna. Fuera de esta línea, se extendía una rica y fértil tierra que recibía el nombre de Pago de Ñuñohue, antiguo territorio indígena dedicado a la producción agrícola (De Ramón 1992). Dicha área se estructuraba en torno a numerosos callejones rurales. Sin embargo, había dos caminos que dieron origen a la zona oriente de Santiago: el camino de Las Condes y el camino de Ñuñoa.

Antes de la llegada del siglo XX, la vida urbana en Santiago sufrió un fuerte deterioro, producto de una carencia considerable tanto de áreas verdes como de espacios de ventilación, lo que derivó en profundos problemas higiénicos y pestilencias. Además, surgió de manera masiva la infravivienda encarnada en los cités, conventillos, poblaciones 'callampa' y otras tipologías de la precariedad. Por su cercanía al casco urbano y sus mejores condiciones sanitarias, se instalaron en la periferia oriente de la ciudad tres instituciones que detonaron el proceso de urbanización: la Casa de Huérfanos de las Monjas de la Providencia, el Seminario Conciliar de los Ángeles Custodios y el Hospital Salvador (Recabarren 2008). Así, se crea la comuna rural de Ñuñoa en 1891, de la cual se desprendió, posteriormente, Providencia en 1897 (Valenzuela 1996). Como puede apreciarse en el actual trazado de las calles de la zona comprendida entre las avenidas Providencia e Irarrázaval (figura 1), su urbanización se hizo de forma dispersa, en torno a los callejones rurales existentes (De Ramón 1985). Para el primer tercio del siglo XX. Providencia ya era una urbanización prestigiosa, con poblaciones habitadas principalmente por inmigrantes extranjeros de alto nivel socio-económico y relevancia en la vida social y cultural de la época, atraídos por la idea de empezar una urbanización desde cero, con un estilo de vida rural y libre de los 'males' que caracterizaban a la metrópolis (León 1972; Palmer 1984; Valenzuela 1996). Se trataba de sectores progresistas cuya colonización instaló nuevos modos de vida y formas de habitar la ciudad, construyendo avenidas arboladas rodeadas de numerosas y cuidadas áreas verdes, clubes deportivos e instituciones privadas de educación y cultura, moldeando unos territorios que posteriormente constituyeron los primeros atisbos de la Ciudad Jardín en Chile (Palmer 1984). Sin embargo, la apertura de nuevas avenidas coexistía con antiguos caminos rurales, existiendo ranchos de peones y campesinos dedicados a la agricultura, actividad que se seguía realizando a la par con la urbanización fragmentada de determinados paños de terreno. Dichos vestigios pueden encontrarse hasta el día de hoy en las acequias que corren tímidamente entre sus anchas aceras embaldosadas y sus cuidadas calzadas de asfalto.

Con el devenir de las últimas dos décadas del siglo XX, el poblamiento de la periferia de Santiago alcanzó su mayor apogeo con la búsqueda de viviendas de construcción más reciente y terrenos de mayor tamaño. Dicha consolidación de la expansión de Santiago vino acompañada de la construcción de autopistas y otras infraestructuras que permitieron que el Cono de Alta Renta ${ }^{2}$ se extendiese hacia el piedemonte de la Cordillera de Los Andes en Las Condes, y se urbanizara el sector de La Dehesa en Lo Barnechea y el valle de Chicureo en Colina. A lo anterior, se suma una renovación de las viviendas de sectores más tradicionales de Las Condes y

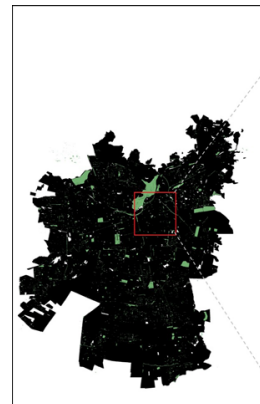

Santiago de Chile

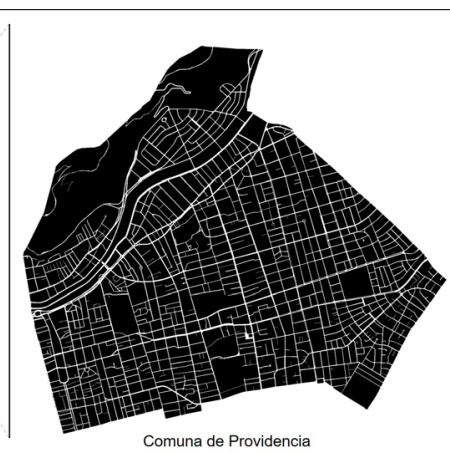

Comuna de Providencia
Figura 1. Tejido urbano de la comuna de Providencia y su localización en el Gran Santiago (fuente: Elaboración propia).

Vitacura, así como la subdivisión de antiguas parcelas en La Reina para la construcción de condominios cerrados (Hidalgo 2004; Meyer y Bähr 2004).

Así, con la llegada del siglo XXI, las comunas de Providencia y Ñuñoa se posicionaron en una condición de centralidad, consolidándose el sector conocido como las Dos Providencias como una continuación del centro financiero, gracias al aporte de un seccional del Plan Regulador y la proyección de un sistema de desarrollo de espacios públicos por incentivos por parte del arquitecto y planificador Germán Bannen (Schlack 2011). Se generó una potente oferta de empleo ligada al sector terciario, atrayendo principalmente a profesionales adultos jóvenes que buscaban residencia cerca de sus lugares de trabajo. Se desató una creciente densificación y construcción en altura en torno a los ejes principales de estas dos comunas (López-Morales, Gasic y Meza 2012), ya que la gran oferta comercial y cercanía a estaciones de metro las convirtió en excelentes localizaciones residenciales. Esta fuerte demanda y la restricción a la construcción en altura a partir de la regulación municipal han aumentado exponencialmente los valores del suelo en la última década. 


\section{DE POBLACIÓN A BARRIO: EI Aguilucho como urbanización en la periferia de Santiago. El actual} barrio El Aguilucho corresponde a la antigua Población San José (y partes de la Población Colo-Colo y La Reforma), siendo una de las primeras urbanizaciones de esta zona, la cual, al momento de su creación, no formaba parte del continuo urbano de Santiago. En efecto, tal como afirma De Ramón: "Cuando los bordes de la ciudad avanzaban hasta tocar los parajes rurales, poblados o no, éstos de inmediato pasaban a ser llamados poblaciones, las que eran bautizadas, para distinguirlas, con el nombre de algún santo o con el apellido del propietario o con otro símbolo cualquiera" (1985: 210). El concepto de población se utilizó "para definir cualquier agrupación de edificios y calles" (De Ramón 1985: 214). Sin embargo, a través del tiempo el concepto fue mutando y adquiriendo nuevas connotaciones. Así, por ejemplo, a mediados del siglo XIX caracterizaba principalmente a aquellos conjuntos destinados a la clase media. Más tarde, aparecerían los primeros atisbos de la idea de población que se generalizó en la segunda mitad del siglo $X X$, haciendo referencia a asentamientos informales habitados por personas en extrema pobreza, y que han sido identificados hasta nuestros días como 'población callampa'.

Una de las características esenciales del concepto de población al que aquí se hace referencia, es que los conjuntos debían localizarse en la periferia de la ciudad. La Población San José corresponde a la urbanización de la antigua Chacra San José, vendida por José Luis Gandarillas en

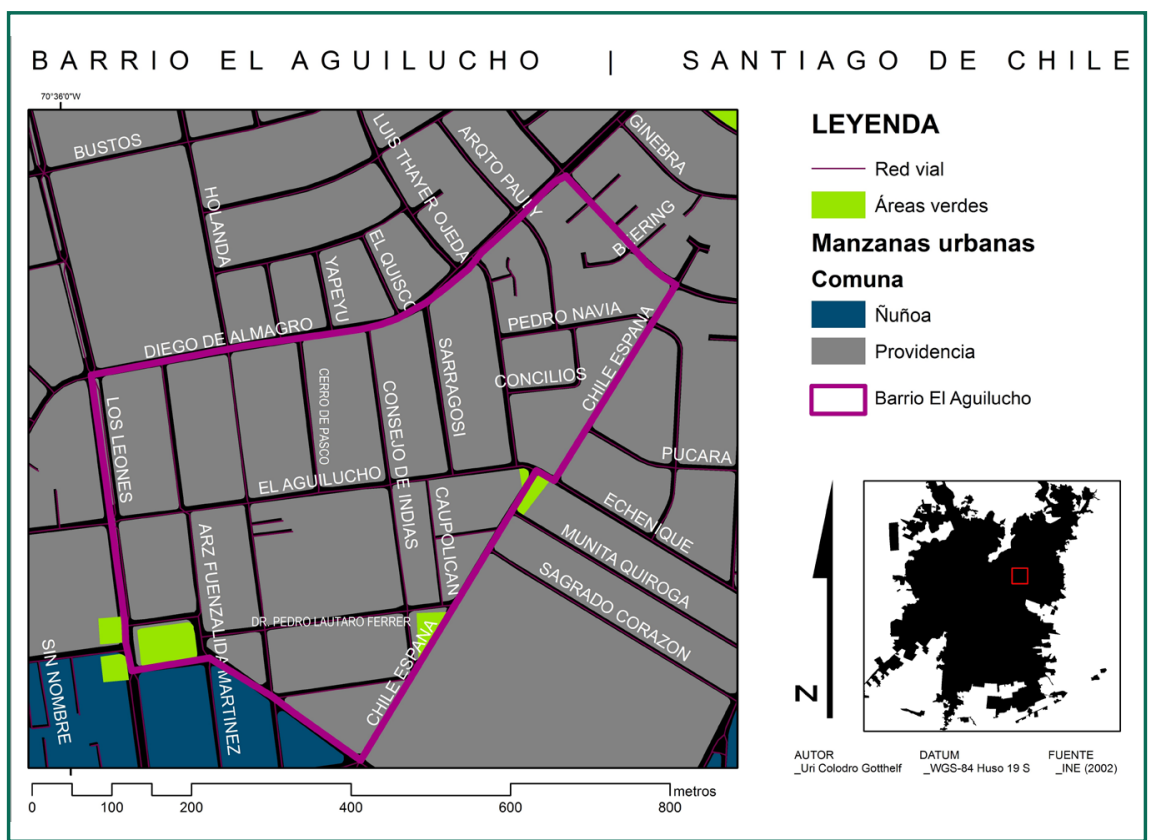

Figura 2. Plano del actual barrio El Aguilucho (fuente: Elaboración propia).

$\$ 43.000$ el año 1896 (De Ramón 1985)3. Ese mismo año se comenzaron a vender los primeros sitios, siguiendo un trazado ortogonal que se deforma de acuerdo a los antiguos límites y caminos pre-existentes. Resulta relevante destacar el papel de las calles que componen el barrio y sus recorridos, ya que son cruciales para entender su contexto morfológico. En su origen, los límites de la Población San José fueron la calle Almagro por el norte (actual Diego de Almagro), Villaseca por el oeste y Bolívar por el sur (actual avenida Simón Bolívar). El límite era difuso hacia el este, definiéndose recién después de 1930 con la construcción del colegio de las Monjas Francesas y la apertura del eje Chile España. La Plaza Septiembre se constituyó como el centro geográfico del barrio, siendo cruzada por las calles Los Leones y Pizarro (actual Doctor Pedro Lautaro Ferrer). Por su parte, el predio del actual Campus Oriente de la
Pontificia Universidad Católica de Chile generaba un corte en diagonal hacia el suroeste, el cual fue moldeado a través de la calle Santa Clara (figura 2). En los años sesenta, esta posición se aprovechó para abrir el eje Diagonal Oriente a partir de estudios realizados por Karl Brunner y fue planificada en 1932 (Muñoz 2007).

Al tratarse de una de las zonas más antiguas de la actual comuna de Providencia, su evolución temporal ha constituido un espacio de coexistencia que agrupa diversas tipologías constructivas, así como una renovación de habitantes en los últimos años. Como se observa en la imagen 1 , algunas calles del barrio han heredado las casas más antiguas de fachada continua. Sin embargo, estas se entremezclan con otras viviendas que responden a la tipología de Ciudad Jardín, así como con edificios de departamentos de arquitectura innovadora y reciente (imagen 2 ). 


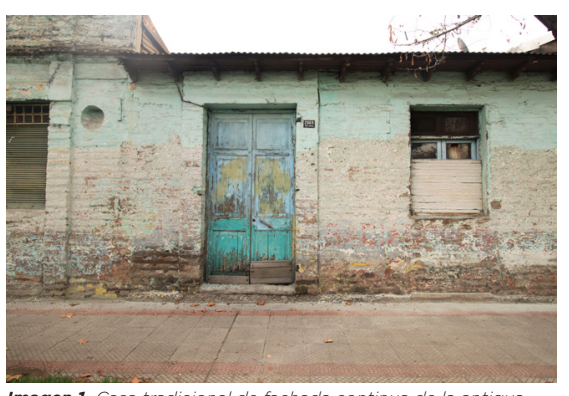

Imagen 1. Casa tradicional de fachada continua de la antigua Población San José, Avenida Holanda (fuente: Archivo personal de Pascuala Beckett 2017).

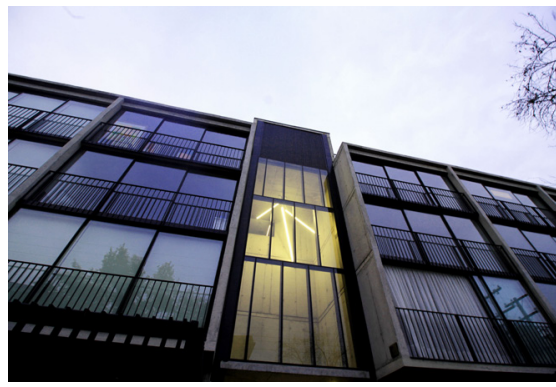

Imagen 2. Las nuevas tipologias habitacionales construidas en el barrio responden a otras lógicas socio-económicas. Ejemplo de ello son edificios de departamentos dúplex y casas bajo la modalladad de townhouses. Edificio en Calle Doctor Pedro Lautaro Ferrer (fuente: Archivo personal de Pascuala Beckett

\section{LA FRAGMENTACIÓN DE LA} POBLACIÓN SAN JOSÉ: LOS orígenes del actual barrio El Aguilucho. A partir

de la construcción de nuevas poblaciones, en los años sesenta ya se encontraba prácticamente urbanizada toda esta zona de Ñuñoa, así como también la vecina comuna de Providencia. Las chacras de Lo Cerda y El Belloto se habían convertido en las poblaciones Sudamérica y El Belloto. Lo que quedaba de la chacra de Los Leones ya estaba completamente urbanizada, acogiendo además al colegio San Ignacio (Muñoz 2007). En 1971 la antigua Congregación del Sagrado Corazón de Jesús pasó a manos de la Pontificia Universidad Católica de Chile, inaugurando el Campus Oriente de esta casa de estudios. Asimismo, la antigua calle Carmen fue rebautizada en los años cincuenta con el nombre de Los Aguiluchos ${ }^{4}$, topónimo que pasó a caracterizar al barrio en adelante,

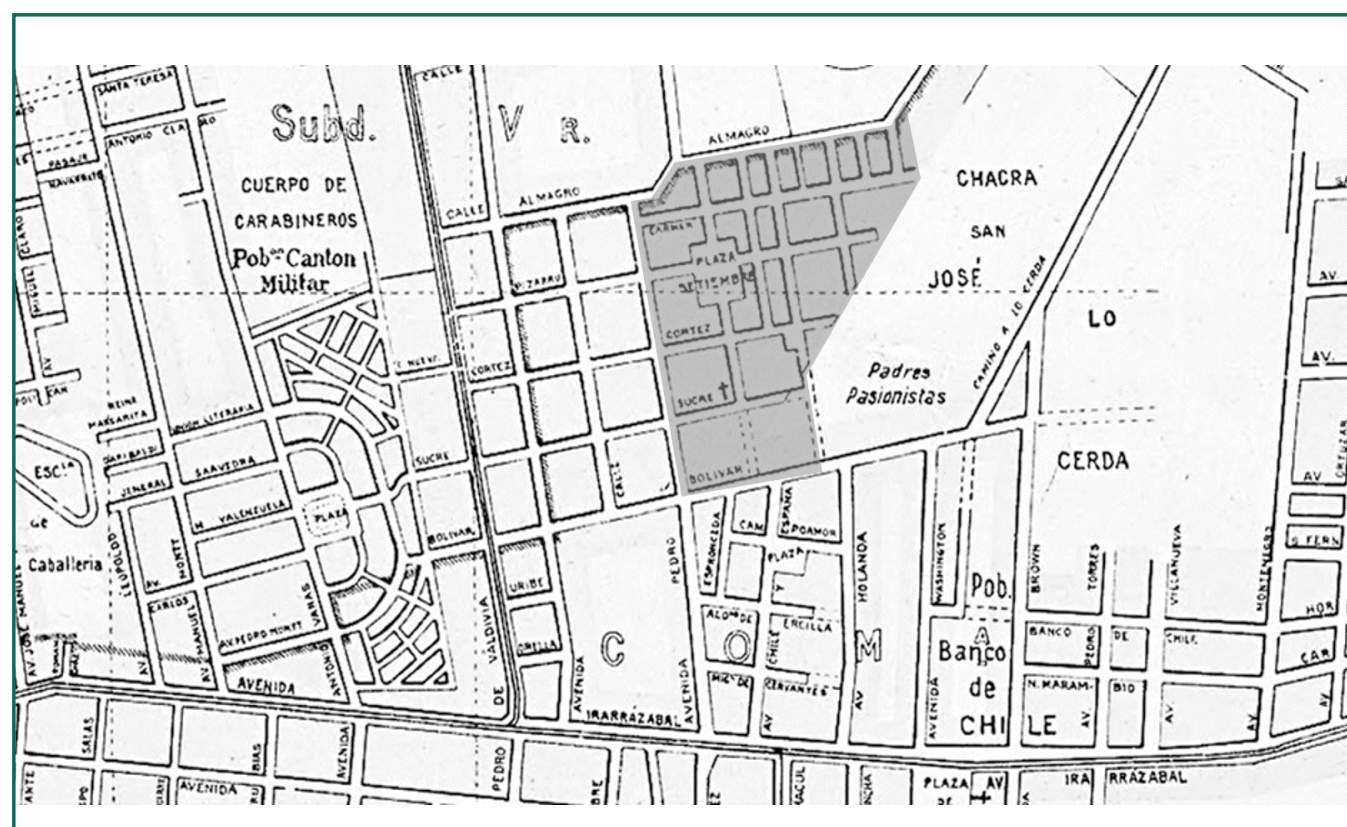

Figura 3. Plano de la Ciudad de Santiago (año 1930). Detalle de la Población San José (fuente: Biblioteca Nacional de Chile).

dejando en el olvido su pasado como Población San José.

El rápido desarrollo urbano que caracterizó a esta zona de Santiago comenzó a requerir de la apertura de nuevos ejes, dado el incremento del uso del automóvil y la llegada de buses motorizados que operaban el transporte público de la época. Así, en la década de 1960, Los Leones se consolidó como un eje principal de transporte y, a su vez, se abrió la ya citada Diagonal Oriente. Ambas avenidas fragmentaron el barrio, situación morfológica que dista de lo que se evidencia en un mapa de 1930 (figura 3), donde se configuraba como una sola unidad, con su plaza como centro. Actualmente, la plaza es un elemento accesorio, a un costado del barrio. El año 1982, en un proceso de reorganización político-administrativa de todas las comunas de Chile, se decidió ampliar los límites de la comuna de Providencia (llustre Municipalidad de
Providencia 2007). Con ello, uno de los territorios más simbólicos de la clase alta santiaguina heredó antiguos barrios de la comuna de Santiago en torno a la avenida General Bustamante; señoriales chalés de Pedro de Valdivia Norte originarios de la comuna de Las Condes; y toda la franja norte de la comuna de Ñuñoa. Con ello, la mayor parte del barrio El Aguilucho pasó a formar parte de la comuna de Providencia, acentuando aún más la fragmentación realizada con la apertura de ejes viales en los años '60s. Así, en términos de identidad, El Aguilucho se consolidó en las décadas siguientes como un barrio propio de Providencia. Las áreas rezagadas, que hoy siguen formando parte de Ñuñoa, se han consolidado como espacios más funcionales, sufriendo fuertes transformaciones con la construcción de condominios verticales, supermercados de grandes superficies y colegios, entre otros equipamientos. 


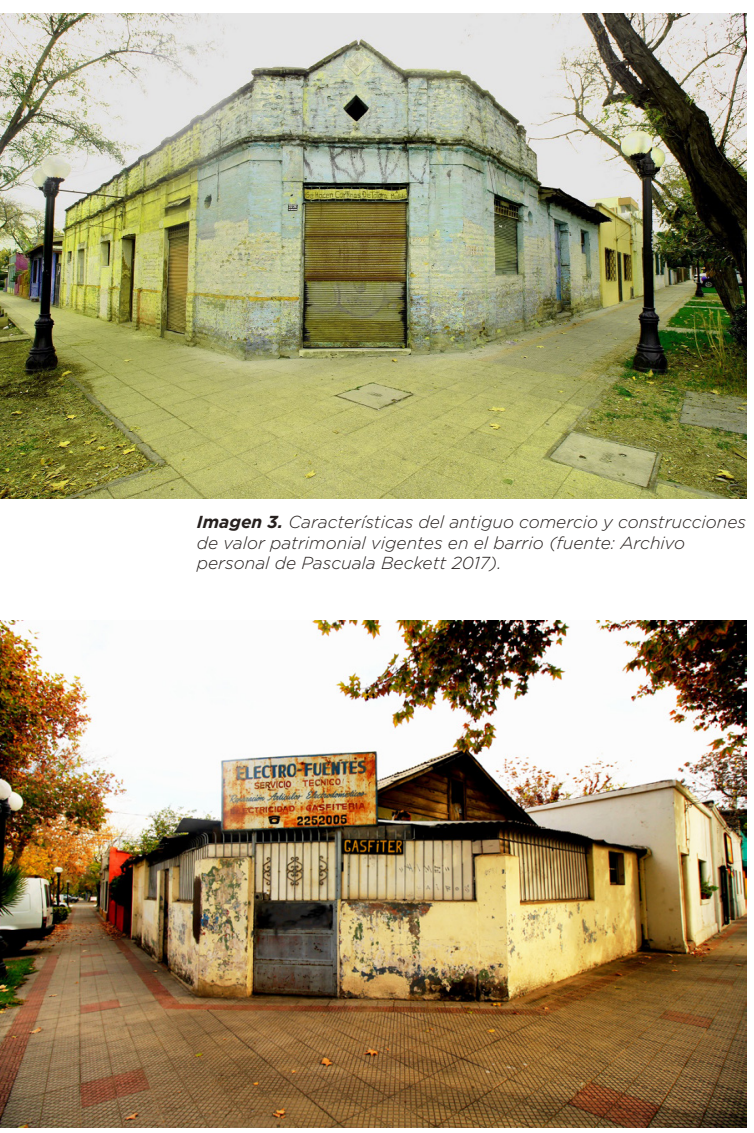

Imagen 4. La antigüedad y los origenes del barrio configuran una situación particular de marcada heterogeneidad social. En barrio confluyen vecinos y locatarios de distintos grupos etarios de Pascuala Beckett 2017).
UN BARRIO HABITADO: El valor de El Aguilucho como territorio de

Providencia. La Población San José

quedó inserta en una zona destinada a grupos acomodados, con características paisajísticas que difieren del modelo de ciudad jardín y habitantes encarnados en gente sencilla y de clase trabajadora que no tiene sus orígenes en la élite santiaguina. Tampoco ha sufrido la misma evolución que el resto de su entorno, que en los últimos años se ha caracterizado por una fuerte densificación y construcción en altura. En este sentido, destaca lo que sostiene De Ramón, al afirmar que "la sola circunstancia de crecer dejando a la primera periferia ahora en una ubicación más central, no es garantía de que ésta evolucione hacia otros niveles tanto en habitación como en infraestructura. Esto puede observarse en ciertas 'islas' que muchas veces permanecen dentro de áreas que han tenido otra evolución" (1985: 220). Lo anterior sucede en este caso, donde el barrio en estudio no comparte con sus barrios vecinos la misma morfología, orígenes sociales y prácticas culturales.

Con respecto a las actividades que se realizaban en el barrio, Palmer (1984) documenta que para el año 1971 había seis industrias dedicadas a productos alimenticios, madera y corcho, material de transporte, productos químicos, calzado, cuero y textiles. En este sentido, se destaca el carácter mixto que ha tenido desde sus inicios, albergando no solo actividades residenciales sino que también fabriles de bajo impacto y comercio. Esta situación se repite en prácticamente toda la comuna de Providencia y también Ñuñoa, a pesar de que existieron focos específicos de industria en el actual Barrio Italia y el sector sur de Ñuñoa, que todavía conserva este carácter. La relevancia comercial del barrio se evidencia a través de su consolidación reciente, y a través de la relevancia simbólica que han tenido algunos de sus principales locales hasta la actualidad, destacándose su valor y autenticidad. Ejemplo de ello son algunas cantinas, restaurantes típicos del Mercado Diego de Almagro, antiguos oficios como la restauración de muebles, carpintería, reparadoras de ropa y calzado, enmarcaciones y panaderías populares, entre otros (imágenes 3 y 4). Su existencia, incluso en el caso de aquellos locales que ya no están, ha quedado plasmada en el imaginario local ${ }^{5}$, como lo ejemplifican el mítico bar Donde Bahamondes, el Jardín California y otros negocios que en algunos casos han sido renovados o reemplazados por equipamiento comunal. Como se observa en una revista de tiraje local del año 1953, destaca entre la publicidad el variado comercio presente en un barrio que, como pocos en Santiago, ha conservado ese carácter mixto (figura 4).

En este sentido, y teniendo esta idea de comercio y mixtura social, sus propios habitantes lo caracterizan como 'El Pueblito de Providencia'. Esta singularidad se genera gracias a la tipología de algunos locales 'encapsulados en el tiempo', así como a un nuevo comercio asociado a grupos de mayores ingresos. Ambos casos, sin embargo, comparten que en su totalidad son pequeños emprendimientos de carácter local, comúnmente atendidos por sus propios dueños, quienes residen también en el barrio o en sus proximidades. Dicha situación se complementa con una segunda característica, asociada al valor de las relaciones sociales e interacciones que se producen en su interior, gracias a la temporalidad de esos vecinos 'de toda la vida' y al sentimiento de comunidad que ha permitido ir incorporando a aquellos nuevos que llegan a habitar el barrio. Así, la escasa densificación que ha sufrido este perímetro juega un rol esencial, a pesar de la existencia de transformaciones socio-territoriales recientes que tienen que ver con un recambio generacional y de renovación urbana.

Los tejidos sociales construidos en esta pequeña burbuja de Providencia se caracterizan especialmente por su solidez; la conversación con la arquitectura de fachada continua y ampliación del espacio público en las intersecciones principales a 

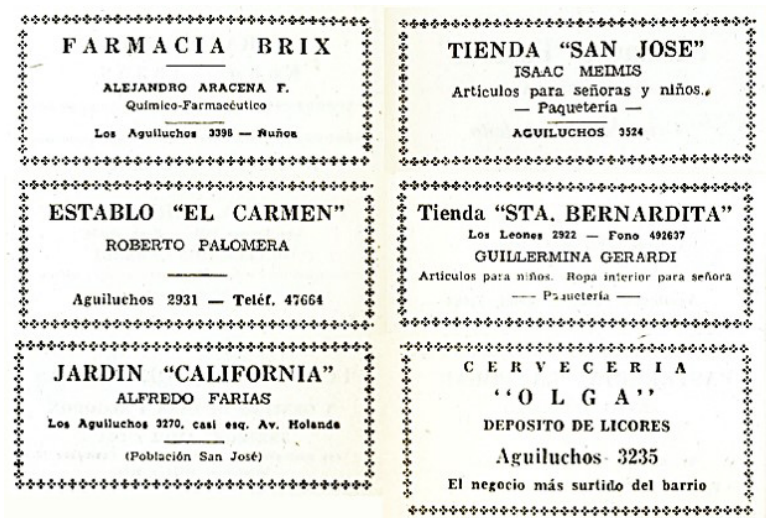
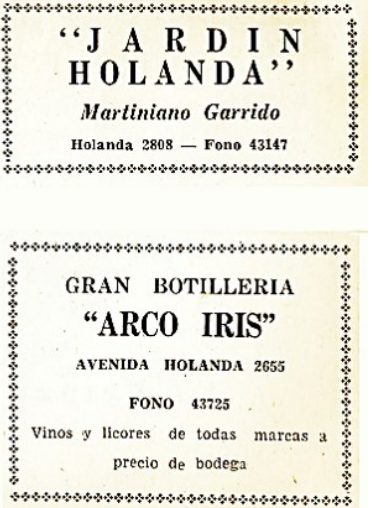

Figura 4. Avisos de algunos comercios en la antigua Población San José (año 1953) (fuente: l/ustre Municipalidad de Nuñoa 1953).

través de la existencia de chaflanes; y una prolongación de la vivienda mediante la satisfacción de las necesidades cotidianas con un comercio de cercanía personalizado. Dichas relaciones se consolidan al existir elementos activadores como la Asociación Gremial Barrio El Aguilucho, que aglomera a los comerciantes del barrio, así como prácticas no institucionalizadas pero que sí rescatan un enorme valor en pos del fortalecimiento endógeno de la economía local, como la utilización de proveedores procedentes del barrio. En la práctica, esto se expresa, por ejemplo, en una de las cafeterías que se abastece de la verdulería localizada en frente y la florería de unas cuadras más allá, ayudando, además, a vecinos artistas emergentes a exhibir sus obras y traer bandas locales para que toquen en veladas más bohemias.
CONCLUSIONES.

El presente trabajo aporta con la recopilación del contexto histórico del barrio El Aguilucho, tratándose de un insumo que permite comprender y analizar los procesos y fenómenos que experimenta este territorio a nivel social, residencial, comercial e inmobiliario.

La evolución relatada desde su fundación en 1896 hasta los tiempos actuales ha conferido unas características y valores singulares que hacen que se distinga de manera nítida de sus territorios vecinos. La llegada del siglo XXI también ha tenido una particular implicancia, dando paso a la coexistencia de un comercio 'encapsulado en el tiempo' y a una red de residentes asociada a la clase obrera con la llegada de otros grupos sociales, con mayor poder adquisitivo y capital cultural.
En este sentido, la continuidad de estos modos de vida dependerá de las estructuras de gobernanza que encaucen las transformaciones socio-territoriales en curso, caracterizadas principalmente por una gentrificación comercial y un aumento sostenido y exagerado del precio del suelo en los últimos años. Se ha generado un interés por el barrio de parte de grupos de ingresos más elevados, produciéndose transformaciones en el hábitat residencial y en las tipologías constructivas. Así, el área seguirá sujeta a cambios que, en caso de existir determinadas políticas urbanas, dinámicas empresariales y una débil resistencia, podrían derivar en resultados negativos como la expulsión generalizada de residentes de menor poder adquisitivo, la construcción en altura y la consecuente destrucción de los tejidos morfológicos y sociales existentes.

\section{REFERENCIAS}

Biblioteca Nacional de Chile, 1930. Plano de la ciudad de Santiago (material cartográfico). Disponible en: http://www.bibliotecanacionaldigital.cl/bnd/631/w3-article-157183.html

De Ramón, A., 1992. Santiago de Chile (1541-1991). Historia de una Sociedad Urbana. España: Editorial Mapfre. De Ramón, A., 1985. "Estudio de una periferia urbana. Santiago de Chile, 1850-1900". Historia, 20, 199-294. Hidalgo, R., 2004. "De los pequeños condominios a la ciudad vallada: Las urbanizaciones cerradas y la nueva geografia social en Santiago de Chile (1990-2000)". EURE, 30 (91): 29-52.

Ilustre Municipalidad de Ñuñoa, 1953. 58 Años de vida comunal: 1895 - 19 abril - 1953: $2^{a}$ parte: Nuñoa Actual. Publicación oficial de la l. Municipalidad de Nuñoa ordenada por el Alcalde Don José M. Narbona. Santiago de Chile: llustre Municipalidad de Ñuñoa.

Ilustre Municipalidad de Providencia, 2007. Plan Regulador Comuna/ 2007. Memoria explicativa. Secretaría Comunal de Planificación (SECPLA), Departamento de Asesoría Urbana.

León, R., 1972. Nuñohue: Historia de Nuñoa, Providencia, Las Condes y La Reina. Buenos Aires: Francisco de Aguirre.
López-Morales, E., Gasic, l. y Meza, D., 2012. “Urbanismo pro-empresarial en Chile: Políticas y planificación de la producción residencial en altura en el pericentro del Gran Santiago". Revista INVI, 27 (76): 75-114. Meyer, K. y Bähr, J., 2004. "La difusión de condominios en las metrópolis latinoamericanas. El ejemplo de Santiago de Chile." Revista de Geografía Norte Grande, 32, 39-53.

Muñoz, T., 2007. "De hito a trazador: Rol de Campus Oriente en la urbanización de Ñuñoa durante el s. XX." En Bannen, P. y Seisdedos, S. Comp.), Campus Oriente: edificio y ciudad como realidades paralelas. Taller de Investigación, primavera de 2007. Santiago de Chile: Pontificia Universidad Católica de Chile, 1-15. Palmer, M., 1984. La Comuna de Providencia y la Ciudad Jardín. Santiago de Chile: Orograma. Recabarren, J., 2008. "La migración de las elites hacia el oriente de Santiago: el caso de la comuna de Providencia. 1895-1930." Revista Encrucijada Americana, 2 (1): 141-166.

Schlack, E., 2011. "Producción privada de espacio público. Espacios privados de uso público y planificación por incentivos." Revista de Arquitectura, 17 (24): 18-25.

Valenzuela, C., 1996. Providencia: Breve historia de la comuna. Santiago de Chile: Editorial Andújar. 